\title{
Stem cells and their role in pituitary tumorigenesis
}

Gabriela Carreno*, Jose Mario Gonzalez-Meljem*, Scott Haston*, Juan Pedro MartinezBarbera $^{\mathrm{a}}$

Developmental Biology and Cancer Program, Birth Defects Research Centre, Institute of Child Health, University College London. London, United Kingdom

*Authors contributed equally to this work

a Corresponding author: Juan Pedro Martinez-Barbera, Developmental Biology and Cancer Program, Birth Defects Research Centre, Institute of Child Health, University College London. London, WC1N1EH, United Kingdom. Telephone: 44-207-905-2821; Fax: 44-207-831-4366; e-mail: j.martinez-barbera@ucl.ac.uk.

Keywords: pituitary; stem cell; cancer stem cell; pituitary adenoma; adamantinomatous craniopharyngioma 


\begin{abstract}
The presence of adult pituitary stem cells (PSCs) has been described in murine systems by comprehensive cellular profiling and genetic lineage tracing experiments. PSCs are thought to maintain multipotent capacity throughout life and give rise to all hormone-producing cell lineages, playing a role in pituitary gland homeostasis. Additionally, PSCs have been proposed to play a role in pituitary tumorigenesis, in both adenomas and adamantinomatous craniopharyngiomas. In this manuscript, we discuss the different approaches used to demonstrate the presence of PSCs in the murine adult pituitary, from marker analyses to genetic tracing. In addition, we review the published literature suggesting the existence of tumor stem cells in mouse and human pituitary tumors. Finally, we discuss the potential role of PSCs in pituitary tumorigenesis in the context of current models of carcinogenesis and present evidence showing that in contrast to pituitary adenoma, which follows a classical cancer stem cell paradigm, a novel mechanism has been revealed for paracrine, non-cell autonomous tumor initiation in adamantinomatous craniopharyngioma, a benign but clinically aggressive pediatric tumor.
\end{abstract}




\section{Introduction}

The pituitary gland is a master endocrine organ that orchestrates the release of several hormones as a consequence of hypothalamic and peripheral organ signals (Denef, 2008). The finely tuned release of these hormones is essential for many physiological processes such as growth, metabolism and reproduction (Drouin, 2011). During recent years a substantial amount of work has revealed the existence of pituitary stem cells (PSCs), which reside in the embryonic and postnatal pituitary (Castinetti et al., 2011; Vankelecom and Chen, 2013). These undifferentiated progenitor/stem cells have the capability to commit and give rise to all three main pituitary hormone-producing cell lineages (through the activation of essential transcription factors: PIT1, TPit and SF1) and ultimately differentiate into the mature hormoneproducing populations (Dasen and Rosenfeld, 2001; Zhu et al., 2007). These PSCs have been shown to contribute to organ homeostasis and tumorigenesis (Andoniadou et al., 2013; Rizzoti et al., 2013).

In this concise review, we aim to address the growing body of evidence that suggests the importance of PSC in the formation and progression of pituitary tumors. Specifically, we will focus on Adenomas and Adamantinomatous Craniopharyngioma. The regulation of the pituitary stem cells and its signaling pathways is the subject of a separate review in this issue (S. Camper and MI. Perez-Millan, this Issue).

\section{The properties and identity of pituitary stem cells}

Stem cells (SCs) are characterized by the capacity to self-renew and to divide asymmetrically giving rise to progenitors with multipotent differentiation capability. These progenitors can either terminally differentiate or become transit-amplifying cells which further proliferate in order to sustain a pool of undifferentiated tissue-specific progenitors (Hsu et al., 2014). SCs are therefore able to maintain and replenish the pool of tissue-specific progenitor cells which are essential for embryonic development and plastic tissue adaptation, such as that occurring during homeostatic turnover or in regeneration after injury (Patel et al., 2013; van Es et al., 2012).

SCs can be experimentally characterized by the expression of defined stem cellassociated factors (e.g. SOX2, NANOG, OCT4, SCA1 and CD44), their in-vitro clonogenic 
potential or the identification of a side population by flow cytometry (Goodell et al., 1996; Lepore et al., 2005; Puck and Marcus, 1956). A decade of research has provided convincing evidence that adult PSCs exist. Firstly, it was shown that pituitary cells grown in stem cellpromoting media form adherent colonies, which actively uptake the fluorescent dipeptide $\beta$ Ala-Lys-Ne-AMCA and express S100ß, both markers of pituitary folliculostellate cells (FS) (Lepore et al., 2005). These adherent colonies were also able to differentiate into hormone producing cells, indicating their multipotent capacity. Another study reported that nonadherent sphere colonies, referred to as "pituispheres", could be grown in clonal conditions and were shown to express stem cell-associated markers such as OCT4 and NANOG. This pituitary cell population had the capacity to efflux verapamil-sensitive Hoechst dye, which allowed the identification of a side population with SC properties by flow cytometry (Chen et al., 2005). Cells within the side population expressed Stem Cell Antigen 1 (SCA1), showed increased expression of SOX2, SOX9, CD44 and CD133, as well as the activation of developmental pathways essential for stem cell homeostasis and embryogenesis (i.e. Notch, Wnt and Shh) (Chen et al., 2009).

Since the first characterization of PSC populations, several other cell populations have been identified with in-vitro clonogenic potential such as those expressing NESTIN, PROP1, PRX1/2, GFRa2 or CXCR4 (Garcia-Lavandeira et al., 2009; Gleiberman et al., 2008; Higuchi et al., 2014; Horiguchi et al., 2012; Nomura et al., 2009; Rizzoti et al., 2013). NESTIN has been shown to have overlapping expression with SOX2+ cells in the marginal zone (MZ) of the anterior pituitary (AP) and in pituispheres. However, expression of NESTIN is not restricted to PSCs and is heterogeneous, including non-hormonal pituitary cell types (Krylyshkina et al., 2005; Vankelecom, 2007). Expression of PROP1, an essential embryonic pituitary transcription factor, has been confirmed in adult PSCs (Garcia-Lavandeira et al., 2009; Yoshida et al., 2009). Additionally, it has been shown that expression of SOX2+/PROP1+ must be downregulated postnatally for hormonal cell differentiation (Chen et al., 2009; Fauquier et al., 2008; Gremeaux et al., 2012; Yoshida et al., 2009). Recently, it was also shown that PROP1 expression is required to maintain a normal pool of PSCs both embryonically and postnatally by orchestrating an EMT-like process (Pérez Millán et al., 2016). PRX1 and 2 are paired related homeodomain proteins that have been identified in the PSC side populations, including a population of SOX2+/PROP1+ periluminal embryonic pituitary cells (Susa et al., 2012), and it has been suggested that expression of PRX1/2 is essential for the maintenance and proliferation Rathke's pouch progenitor cells up until 
differentiation (Vankelecom, 2010). The chemokine receptor CXCR4 has been found to be expressed in FS cells and in other cells of the AP (Barbieri et al., 2007; Horiguchi et al., 2012). In addition, CXCR4 and its ligand CXCL12 were identified in the stem cell-enriched side population of the mouse pituitary gland (Vankelecom, 2010). The well-known chemotactic and trophic properties of CXCR4 and its ligand suggest a possible role for migration and maintenance of PSCs (Barbieri et al., 2007). Finally, a population expressing GFR $\alpha 2$, RET and PROP1 (referred to as "GPS" cells), as well as other SC markers, has been proposed to form part of a SC niche located in the MZ of the pituitary lumen and it has been suggested they may play a role in PSC regulation, including cell survival or structural guidance of these cells (Garcia-Lavandeira et al., 2009). This putative SC population was identified in both human and mouse pituitaries and expresses progenitor markers SOX2, SOX9 and OCT4. Half of the GPS population also expressed S100 $\beta$. Additionally, when GFR $\alpha 2+$ cells were isolated from mouse pituitaries they could be cultured as spheres and could be differentiated into hormoneproducing cell types. Furthermore, an appealing proposal involving the GPS population was recently introduced by Garcia-Lavendeira et al., and concerns a mechanism for the regulation of pituitary cell turnover (a largely unexplored subject) through the apoptosis of differentiated cell types by the RET/Pit-1/Arf/p53 pathway (Garcia-Lavandeira et al., 2015).

SOX2 expression has been shown to be exclusively expressed in both adherent and non-adherent PSC colonies in clonal culture (Andoniadou et al., 2012; Fauquier et al., 2008). SOX2 is a pluripotency-associated factor expressed in embryonic stem cells, induced pluripotent cells and shown to be important for the maintenance of stem cells in various adult tissues. A subset of SOX2 PSCs of the postnatal AP resides in the MZ and are thought to be part of the presumptive progenitor/stem cell niche. SOX2+ cells are also expressed throughout the AP parenchyma, where SOX2 expression does not overlap with differentiated hormonal cells. However, only a small proportion of postnatal SOX2+ cells retain self-renewing clonogenic potential when sorted and maintained in clonal culture (2.5-5\%) (Andoniadou et al., 2013). This could suggest that not all SOX2+ cells of the AP retain stem cell capacity. Furthermore, lineage tracing of SOX2+ cells in the postnatal AP revealed their long-term persistence and multipotent differentiation capability, as they were shown to give rise to all AP hormone-producing cell types throughout life (Andoniadou et al., 2013; Rizzoti et al., 2013). Interestingly, SOX2 expression mostly overlaps with SOX9, and partially overlaps with S100 $\beta$ in the AP marginal zone, while it was shown that sorted S100 $\beta+$ cells possess increased 
clonogenic potential (Rizzoti et al., 2013). Therefore, current evidence suggests SOX $2+/ \mathrm{S} 100 \beta+$ cells represent a type of adult PSCs.

Finally, there is evidence supporting the existence of PSCs in humans. In one study, isolation and culture of pituispheres derived from 5 patients after autopsy was reported. The resulting pituispheres were shown to express NESTIN, pituitary-specific markers $L H X 3$ and PITX2 after several passages, as well as expressing all six pituitary hormones (Weiss et al., 2009). In another study, authors identified a GPS population similar to that shown to exist in mouse pituitaries. This population was located in the MZ and showed the expression of stemness-associated factors SOX2, SOX9, OCT4, KLF4 and GFRA3 (Garcia-Lavandeira et al., 2011)

In summary, there has been extensive characterization of candidate PSC populations which express stem cell associated markers and display stem cell related features. However, "stemness" marker expression alone, is not sufficient for defining a SC population. For example, S100 $\beta+$ cells appear to be a heterogeneous population encompassing folliculostellate cells and also subsets of stem cells, committed progenitors and pituicytes of the postnatal pituitary (Sato et al., 2005; Soji et al., 1997; Yoshida et al., 2016). Furthermore, expression of NESTIN is not restricted to PSCs, but has been shown to be expressed in pericytes and nonhormonal pituitary cell types (Galichet et al., 2010; Krylyshkina et al., 2005; Vankelecom, 2007). Therefore, further experiments are needed in order to properly assert putative S100+ and NESTIN+ subsets as PSCs. Ultimately, long-term lineage tracing in vivo of these populations would demonstrate their persistence and their ability to give rise to differentiated progeny.

\section{Cancer stem cells and the cancer stem cell model}

Similar to the presence of tissue specific stem cells, experimental evidence has revealed the presence of multipotent cells thought to continuously propagate cancer cells within tumors (Kreso and Dick, 2014; Nakanishi et al., 2013; Schepers et al., 2012; Zomer et al., 2013). These cancer stem cells (CSCs) possess many similarities to normal tissue specific stem cells, as they retain the capability to self-renew, give rise to cancer cell progenitors with multipotent differentiation potential, can be slow-cycling/quiescent (e.g. neural stem cells) or divide rapidly (e.g. crypt stem cells), and are resistant to chemotherapeutics and radiotherapy (Abdullah and Chow, 2013; Stange and Clevers, 2013). CSCs are of great clinical relevance as they are 
thought to drive tumor cell propagation and give rise to the bulk of the tumor mass cellautonomously. Together with their persistent self-renewal and resilience to chemo and radiotherapy, CSCs are thought to be responsible for driving tumor recurrence and progression after conventional treatment. Therefore, cancer therapy should aim to target both the bulk of the proliferating tumor mass, and the small proportion of tumor-driving CSCs that may persist after common cancer treatments.

In some tumors, it has been shown that normal tissue specific SCs can be transformed into oncogenic CSCs (Nakanishi et al., 2013; Schepers et al., 2012; Zomer et al., 2013), while some cancers have been found to be driven by oncogenic transformed progenitor or differentiated cell types (Clevers, 2011; Valent et al., 2012). Irrespectively of the cell of origin (i.e. the cell sustaining the first oncogenic hit), the prevalent view is that at any given point in cancer progression, there is only a subset of cells (CSCs) capable of self-renewal and with the proliferative potential necessary to give rise to the bulk-mass of the tumor (Kreso and Dick, 2014; Visvader and Lindeman, 2008).

CSCs were first isolated from leukemia, however their presence was later demonstrated in multiple types of solid tumors (Al-Hajj et al., 2003; Guo et al., 2008; Nguyen et al., 2012; Visvader and Lindeman, 2008). These studies helped establish common features shared by CSCs that can be useful for their identification, such as the expression of stem cell-associated markers. However, the accepted definition of CSCs requires their identification in situ by lineage tracing and/or serial orthotropic transplantation, most commonly in immunocompromised hosts (Alison et al., 2008; Clarke and Fuller, 2006; Clevers, 2011). This allows clonal tracking in serially transplanted hosts, as daughter tumors will phenocopy the primary tumor and indicate the presence of a CSC able to propagate the tumor. 


\section{Cancer stem cells in pituitary adenomas}

\section{Overview of pituitary adenomas and their pathogenesis}

Pituitary adenomas are among the most common intracranial neoplasms (up to $15 \%$ ) and cross-sectional studies have found a prevalence of around 90 cases per 100,000 inhabitants, with the vast majority being adults over 30 years old (Karavitaki, 2012). The occurrence of true pituitary carcinomas is extremely rare, meaning that most cases are benign in terms of their histopathological features (Shlomo Melmed, 2011). However, their clinical management can be complicated due to hormone hypersecretion (Zhou et al., 2015) or the development of aggressive behavior characterized by resistance to treatment, high proliferative index, recurrence and invasion of nearby tissues (Chatzellis et al., 2015; Del Basso De Caro et al., 2016; Di Leva et al., 2014).

Adenomas can be classified as either: 1) hormone secreting adenomas, as defined by the presence of one or more hyperplastic pituitary endocrine populations (lactotrophs, gonadotrophs, somatotrophs, corticotrophs and thyrotrophs); or 2) non-functional adenomas, which are thought to be mainly derived from gonadotroph cells (Melmed, 2015).

Despite their significant prevalence in the population, the etiology and pathogenesis of pituitary adenomas have only recently begun to be addressed from a molecular point of view. Some groups have provided insights into the clonal and mutational landscape of these tumors, information which could be used for efficient patient risk stratification and appropriate therapy selection.

The most accepted view is that the majority of the pituitary adenomas are monoclonal in origin, as determined by X-chromosome inactivation assays (Alexander et al., 1990; Herman et al., 1990; Ma et al., 2002; Schulte et al., 1991). However, this idea has been contested by studies were X-chromosome inactivation and Loss of Heterozygosity (LOH) analysis were combined and showed different clonal origins in adenomas before and after recurrence (Clayton et al., 2000), as well as in between primary tumors and distant metastases in malignant adenomas (Buch et al., 2002; Clayton and Farrell, 2006). These discrepancies could be attributed to tissue sampling variability but also suggest that more than one cell population with 
tumorigenic capacity can exist at distinct points during the tumorigenic process, at least in a proportion of pituitary adenomas.

A wealth of evidence has recently accumulated regarding key dysregulated genes and mutations relevant to the pathogenesis of pituitary adenomas in both mice and humans (Gadelha et al., 2013; Lines et al., 2016). From this list, the aberrant expression of genes including: PTTG, RB, CDKN1A, CDKN2A and CYCLINS A1, B1, B2, E1 and D1; makes cell cycle dysregulation stand out as a cellular process commonly altered in pituitary adenomas (Aflorei and Korbonits, 2014). However, the true significance of associating pituitary adenoma pathogenesis with any mutations and/or dysregulated pathways can only be understood when these are studied under a hypothesis-driven theory of carcinogenesis, such as the cancer stem cell model (e.g. are these genetic and cellular alterations occurring in the cells responsible for feeding tumor growth?).

\section{The identification of cancer stem cells isolated from pituitary adenomas}

Evidence supporting the existence of cancer stem cells in tumors and leading to the development of the CSC model has existed for more than two decades now and continues to increase (Beck and Blanpain, 2013; Kreso and Dick, 2014). However, the existence of CSCs in pituitary adenomas has only recently begun to be investigated.

$\mathrm{Xu}$ et al. reported for the first time the isolation of tumor cells from human somatotroph and non-functioning adenomas which fulfilled several characteristics of CSCs (Xu et al., 2009). When cultured in stem cell promoting media, the isolated cells formed floating sphere colonies and expressed well-known stem cell markers such as: OCT4, CD133 and NESTIN. These sphere colonies could be subcloned in culture, expressed pituitary-specific genes like $C G A$ (encoding alpha GSU) and PIT1, and could be differentiated into pituitary hormone expressing cells in culture. Importantly, these cells could be serially transplanted into mice and gave rise to pituitary-hormone producing tumors. A second independent study reported similar results where sphere colonies derived from pituitary adenomas also expressed CD133 and NESTIN in culture and gave rise to slow-growing, synaptophysin-positive tumors after subcutaneous xenotransplantation (Chen et al., 2014). 
Another study reported the identification of tumor cells with a side population profile present in a large cohort of human pituitary adenomas (Mertens et al., 2015). Gene expression profiling of this tumor side population (TSP) revealed the expression of CSC-related genes CD44, CXCR4, KIT, KLF4 and NESTIN. The authors noted that the TSP displayed upregulated expression of genes related to epithelial-to-mesenchymal transition (EMT), mesenchymal identity, and an endothelial phenotype, suggesting the presence of hematopoietic progenitors. After depleting the side population from endothelial and immune cell populations $(\mathrm{CD} 31+/ \mathrm{CD} 45+)$, the authors found increased expression of EMT, stemness, mesenchymal and angiogenesis genes in the purified side population (pSP). These pSP cells expressed stem cell markers SOX2 and NESTIN, formed pituispheres which could be serially passaged and that gave rise to hormone expressing cells corresponding to the adenoma type they were isolated from. Although tumor xenografts could not be achieved in this case, the authors identified a pSP in an established adenoma cell line and demonstrated they possessed increased tumorigenic capacity compared to the main population when injected into SCID mice. Worth noting in this study, chemical inhibition of the chemokine receptor CXCR4 lead to decreased tumor cell proliferation and viability and a significant reduction in xenograft tumor growth. CXCR4 is a well-known CSC marker in other tumors (Fujita et al., 2015; Hermann et al., 2007; Jung et al., 2013; Trautmann et al., 2014; Würth et al., 2014) and the importance of CXCR4 signaling in pituitary adenomas has been suggested by several studies involving human tumors and adenoma cell lines (Barbieri et al., 2014). The findings by Mertens et al. suggest that further understanding of the role of CXCR4 in pituitary adenoma pathogenesis and adenoma CSCs can potentially lead to the development of novel therapeutic strategies for these tumors.

A different cell population with SC-like characteristics in GH-secreting and nonfunctioning pituitary adenomas has also been described (Orciani et al., 2015). By using an adherent cell culture protocol, researchers isolated progenitor mesenchymal cells (PMCs) that showed increased expression of classic pluripotency factors OCT4, NANOG, KLF4 and SOX2. However, these cells also fulfilled the expression profile of surface markers that defines mesenchymal stem cells (MSCs). These PMCs could give rise to osteogenic, lipogenic and chondrogenic lineages and lacked expression of pituitary progenitor genes PITX2, PIT1 and PROP1. Moreover, a CD133+ fraction was found to possess increased migratory capabilities in trans-well migration assays. Although the authors do not directly address the capability of the PMCs to form pituitary hormone cells, their results suggest the existence of more than one cell population with CSC characteristics within tumors, but with totally different identities and 
functions. They also indicate care must be taken in future studies addressing CSC biology as the expression of pluripotency factors and cell surface markers can be shared by unrelated CSCs populations.

Recently, a study reported the derivation of cell lines with SC-like characteristics from several human pituitary adenomas, either through selection in SC-permissive media or by sorting for CD133 expression (Würth et al., 2016). The authors reported isolation of SC-like cells and successful culture establishment from $68 \%$ of the adenomas. These cells could be grown as pituispheres, formed secondary spheres upon dissociation and also expressed SC markers SOX2, OCT4, NESTIN, CD133 and CXCR4. When maintained in stem cellpermissive medium, these cell lines retained their proliferative potential for up to 2 months and could be differentiated into hormone-secreting cells. However, cell-line xenografts in NODSCID mice did not lead to tumor growth. This is in contrast to other studies (described above) which reported successful tumor growth from xenografted pituitary adenoma CSCs (Chen et al., 2014; Xu et al., 2009). Nonetheless, it must be noted that in these studies tumor growth was achieved in relatively small numbers (one and two tumors, respectively). Additionally, Mertens et al. also reported absence of tumor growth with several adenoma samples and different xenograft approaches (Mertens et al., 2015). These discrepancies could be due to methodological differences related to either the use of in vitro culture of CSCs prior to transplantation, the heterogeneity of different tumor samples used in these studies (e.g. somatotropinomas and non-functioning adenomas) or distinct CSC populations with divergent growth dynamics. Investigations using larger cohorts of human samples will be necessary to determine the presence of a serially propagating cell tumorigenic cells able to recapitulate the original tumor. Additionally, further work using genetically-engineered mouse models of pituitary adenomas will provide genetic evidence of the existence of CSC populations, in agreement with the CSC paradigm.

So far there is only one report of CSC isolation from murine pituitary adenomas. Researchers derived cells from intermediate lobe tumors formed spontaneously in $R b+/$ - mice and these cells formed pituispheres, which could be serially passaged, even after dissociation. These spheres additionally expressed stem cell related factors SOX2, NESTIN and CD133 and could be differentiated to all hormone producing cell types. They further identified a SCA1+ tumor cell subpopulation which demonstrated increased sphere forming capacity, enriched stem cell marker expression and importantly, possessed a significant increase in tumor forming 
potential compared to SCA1-negative cultured cells when transplanted into NOD-SCID mice (Donangelo et al., 2014).

The discovery of pituitary adenoma CSCs as well as the evidence for the monoclonal origin of these tumors falls in line with the CSC paradigm. However, further research using lineage tracing and transplantation studies is required in order to strongly assert the relationship between the cells that carry the first oncogenic hit (tumor initiating cells) and the CSCs that feed tumor growth at any given point. 


\section{Non-cell autonomous involvement of stem cells in the development of adamantinomatous craniopharyngioma}

Investigation of another pituitary tumor type known as adamantinomatous craniopharyngioma (ACP) has uncovered that mutated PSCs can promote tumorigenesis in a non-cell autonomous manner, in contrast to the classical CSC paradigm. ACPs are benign tumors of the sellar region that aggressively infiltrate into surrounding structures, such as the brain, optic tracts and associated vasculature (Müller, 2010). The disease most commonly affects children, representing the most common pediatric tumor of the pituitary gland in this age group (Müller, 2014).

Molecular studies have revealed that mutations in the CTNNB1 gene, which encodes $\beta$ catenin, have been observed in the majority of human ACP samples (Buslei et al., 2005). The identified mutations are predicted to result in the stabilization of $\beta$-catenin by interfering with the ability of the protein to be targeted for proteasomal degradation. This stabilization results in accumulation of the protein and subsequent activation of the $\mathrm{Wnt} / \beta$-catenin signaling pathway (Buslei et al., 2007). In corroboration, immunohistochemical analysis of human ACP samples reveals the presence of populations of cell clusters which accumulate nucleocytoplasmic $\beta$-catenin (Figure 1a), indicative of Wnt pathway activation in these cells (Hofmann et al., 2006). These cell clusters are a unique feature of ACP, relative to other pituitary tumor types, and are recognized as a hallmark of the disease (Hölsken et al., 2013). Analysis of human ACPs for the presence of CSC populations has not been performed. Some studies have reported the expression of stem cell markers in human ACPs, such as SOX2, SOX9, OCT4, GFRa3, RET, KLF4 and CD133 (Garcia-Lavandeira et al., 2015, 2011; GastonMassuet et al., 2011; Hölsken et al., 2013). However, functional characterization of these cell populations has not yet been performed.

A study using a genetically-engineered mouse (GEM) model (Hesx ${ }^{\mathrm{Cre} /+}$; Ctnnb1 $1^{\text {lox(ex3)/+}}$ ) demonstrate that the expression of a degradation resistant form of $\beta$-catenin in the precursor of the pituitary gland, Rathke's pouch (RP), is sufficient to drive the formations of tumors similar to human ACP (Andoniadou et al., 2012). RP is an embryonic structure that gives rise to the anterior pituitary and possesses undifferentiated progenitor cells that are able to transiently self-renew and generate all AP hormone-producing cells. Similar to the situation 
observed in human ACP, this GEM model demonstrates the characteristic $\beta$-catenin nucleocytoplasmic-accumulating cells clusters (Figure 1b). Cells possessing self-renewing properties and the ability to differentiate have been observed in this GEM model of ACP (Andoniadou et al., 2012). The murine tumorigenic pituitaries contain up to three times more clonogenic cells in vitro than the pituitary of control mice, suggesting an expansion of a stem cell compartment. Molecular analysis of these cells demonstrates expression of the stem cell markers SOX2 and NESTIN, with absence of pituitary differentiation markers. Furthermore, these cells have a proliferation rate that is 1.7-fold higher than normal PSCs cultured from wild type pituitaries. The ability of these putative CSC from mouse ACPs to generate tumors following transplantation remains to be elucidated.

A further GEM model has been generated $\left(\operatorname{Sox} 2^{\operatorname{CreERT2/+}} ; \operatorname{Ctnnb}^{\text {lox(ex3)/+}}\right)$, which also give rise to tumors resembling some aspects human ACP. For instance, cell clusters showing $\beta$-catenin nucleocytoplasmic-accumulation are present and the tumors are synaptophysinnegative (Andoniadou et al., 2013) (Figure 1c). Genetic linage tracing through recombinationmediated activation of a yellow fluorescent protein (YFP) reporter in SOX2+ cells allowed for the identification of daughter cells derived from these oncogene-targeted SOX2+ PSCs. This analysis revealed that the $\beta$-catenin-accumulating cell clusters are derived from SOX2+ PSCs, however, the tumors lack expression of the YFP reporter, suggesting a different cell-oforigin. Intriguingly, this result indicates that the oncogene targeted SOX2+ PSCs do not cellautonomously give rise to the tumor mass but instead generate these tumors from non-targeted cells in a paracrine manner (Andoniadou et al., 2013). Thus, paracrine tumorigenesis is distinct from the CSC model, as the original mutation-sustaining cell is not the clonal cell of origin from which the tumor develops. 

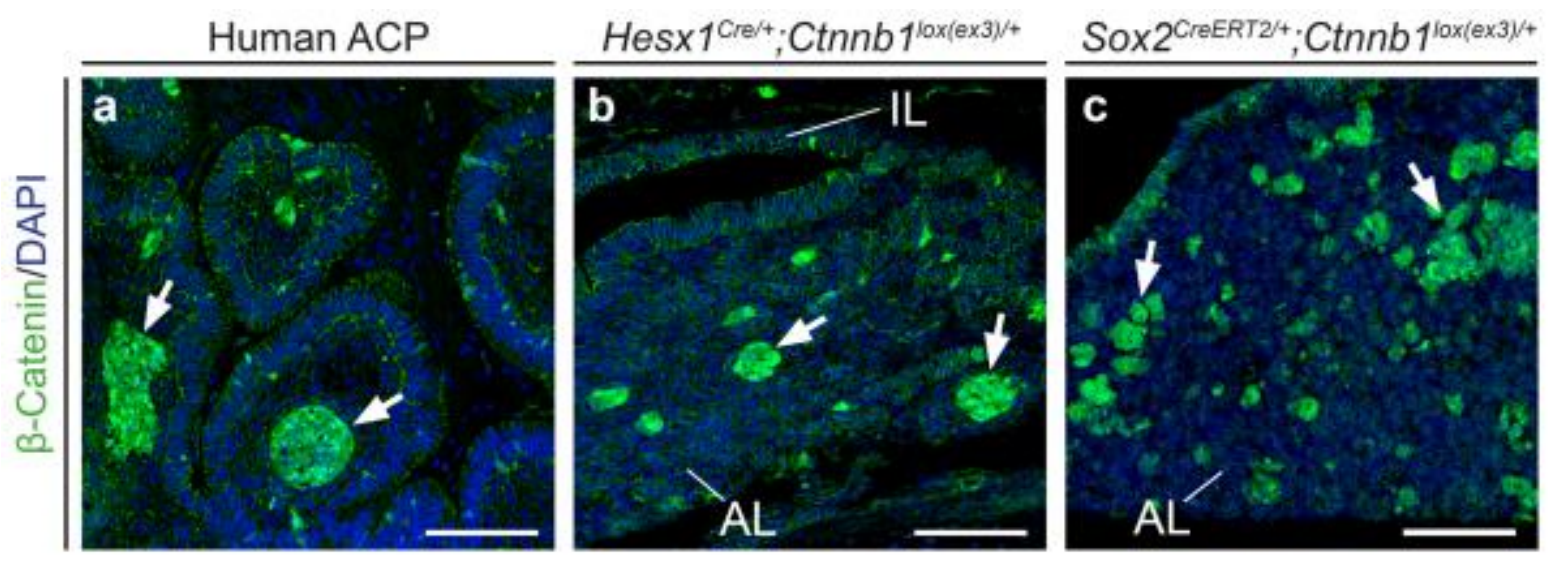

Figure 1. Nucleo-cytoplasmic accumulating $\beta$-catenin clusters are found in human adamantinomatous craniopharyngioma (ACP) and murine models for ACP.

(a) Immunofluorescent staining in human ACP showing the nucleo-cytoplasmic accumulation of $\beta$-catenin in cell groups known as "clusters" (arrows), a defining characteristic of these tumors. (b) Expression of oncogenic $\beta$-catenin in embryonic pituitary progenitors also leads to the formation of clusters in $\mathrm{Hesxl}^{\mathrm{Cre} /+} ; \mathrm{Ctnnbl}^{\text {lox(ex3)/+ }}$ embryos. An $18.5 \mathrm{dpc}$ specimen is shown. (c) Clusters also form upon inducible expression of oncogenic $\beta$-catenin in adult pituitary stem cells of $\operatorname{Sox} 2^{\mathrm{CreERT2/+}} ;$ Ctnnb $^{\text {lox(ex3)/+ }}$ mice. 16 -week post-tamoxifen induction shown. Scale bars: $100 \mu \mathrm{m}$.

It may be possible that the paracrine activities of the oncogene-targeted SOX2+ PSCs induce the formation of CSC that cell-autonomously drive tumor formation. Conceivably, these cell clusters act as signaling centers and promote tumorigenesis either directly or indirectly through cell-cell signaling interactions or microenvironmental changes (Andoniadou et al., 2013). In corroboration of this concept, transcriptomic profiling of $\beta$-catenin-accumulating cell clusters reveals the expression of a plethora of growth factors, chemokines and cytokines, which appear conserved between mouse models and human ACP (Andoniadou et al., 2012). Further studies have revealed a role for several cytokines and growth factors in normal pituitary physiology and in pituitary adenomas (Arzt et al., 1999; Graciarena et al., 2004; Uhrbom et al., 1998).

In support of this emerging model of paracrine tumorigenesis it has been demonstrated that excessive levels of mitogenic signals can result in tumor formation in other systems. The overexpression of platelet-derived growth factor (PDGF) in neural progenitor cells results in 
the formation of neural tumors, which appear similar to human glioma. Human TGF-alpha secretion by rat fibroblasts promotes tumor formation in nude mice (Rogelj et al., 1988). Similarly, basic fibroblast growth factor (bFGF) can induce the transformation of nontransformed cells (Arwert et al., 2010). Evidence for non-cell autonomous tumor or cancer formation has also been provided by GEM models in the skin, liver and hematopoietic system. Skin polyps containing predominantly wild type cells can be generated by targeting the epidermis with a constitutively active form of MEK1, which results in activation of the mitogen-activated protein kinase (MAPK) pathway (Nicolas et al., 2003). Further to this, epidermal or hair follicle deletion of Notchl results in the formation of skin tumors which possess wild type Notch1 (Deschene et al., 2014). Deletion of p53 in hepatic stellate cells induces the formation of epithelial tumors that are primarily wild type for p53 (Lujambio et al., 2013). The most striking example of paracrine transformation in vivo is found in a GEM model of leukemia. In this system, the expression of a degradation-resistant form of $\beta$-catenin in osteoblast precursors is capable of transforming hematopoietic stem cells (HSCs) and give rise to myeloid leukemia (AML). This result can also be achieved though the transplantation of wild type bone marrow to lethally irradiated mice which carry osteoblasts targeted with oncogenic $\beta$-catenin. Further to this, the serial transplantation of these leukemogenic wild type HSC progenitors, but not non-HSC populations, is capable of giving rise to AML in wild type host mice. This suggests that the HSCs have been induced to become CSCs due to the non-cell autonomous activities of the oncogenic $\beta$-Catenin targeted osteoblasts (Kode et al., 2014).

Therefore, the formation of ACP appears to be dependent on PSCs harboring an oncogenic mutation in $\beta$-catenin. However, in contrast to the classical CSC paradigm these mutated somatic stem cells do not cell-autonomously generate the ACP tumor but instead result in the paracrine transformation of a distinct cell type. Such paracrine interactions may favor the emergence of CSC populations that clonally contribute to tumor formation in the pituitary. As ACPs are relatively slow-growing benign tumors, these studies have provided insight into the initial steps of tumor formation, which are mostly over-looked in cancer biology. Therefore, paracrine interactions between SCs and tumor-initiating cells during the initial stages of tumorigenesis could be applicable to many other types of cancer (besides those known for their benign nature) before tumor cells become self-sufficient (Figure 2). 
a

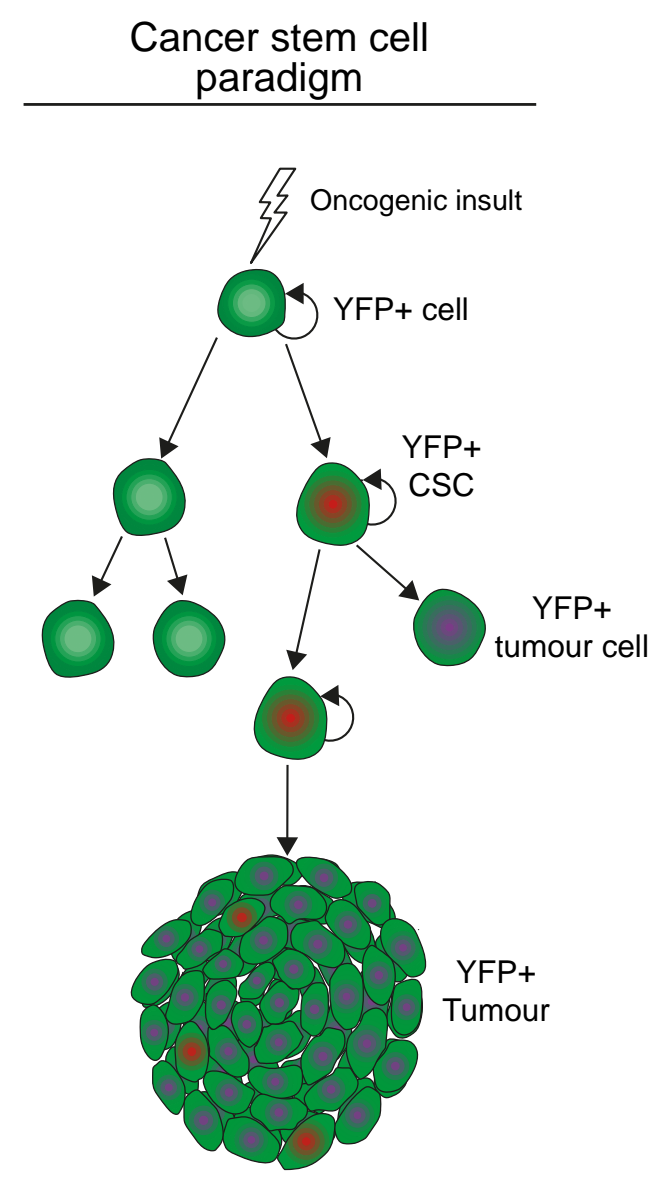

b
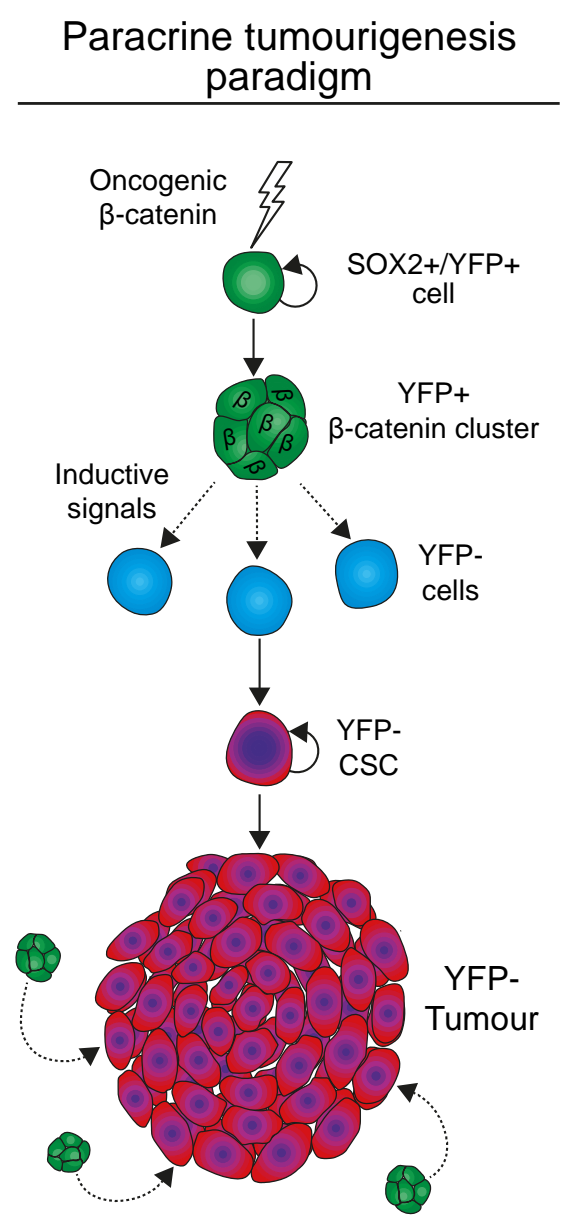

Figure 2. Comparison of different models of tumourigenesis.

(a) The cancer stem cell (CSC) model establishes that an original cell, being either a progenitor, committed or differentiated cell type, is initially transformed by an oncogenic stimulus. This cell's lineage can be traced using a genetic reporter strategy (fluorescent YFP labelling in this example, depicted in green). All the descendants from the original cell carry the oncogenic mutation and express YFP. At some point a YFP+ descendant cell acquires a CSC phenotype (green/red cell) which allows it to self-renew and divide asymmetrically giving rise to differentiated tumor cells (green/purple cell), which form the bulk mass of a YFP+ tumor. (b) The paracrine model of tumourigenesis proposed by Andoniadou et al. states that expression of oncogenic $\beta$-catenin in SOX2+ adult pituitary stem cells leads to non-cell autonomous tumor formation. After a burst of proliferation, targeted cells (also labelled by YFP) form nucleocytoplasmic accumulating $\beta$-catenin clusters. These clusters secrete a plethora of prooncogenic factors which induce the paracrine transformation of a neighboring cell-of-origin, giving rise to a YFP- tumor. Further maintenance or progression of YFP- tumors might also be aided by continuous SASP signaling from the $\beta$-catenin clusters. 


\section{Concluding Remarks}

In conclusion, increasing amount of evidence over the years in mouse and human has provided solid support for the theory that CSCs play a role in pituitary tumorigenesis. Experimental evidence has shown that the classical CSC paradigm model applies to human and mouse pituitary adenomas, in which the oncogenically transformed CSC gives rise to the tumor clonally. Interestingly, analysis of a mouse model for adamantinomatous craniopharyngioma has revealed a critical role for paracrine signaling in non-cell autonomous tumor initiation.

The studies covered in this review highlight the biological and functional heterogeneity of both PSCs and CSCs in pituitary tumor pathogenesis. Therefore, a better understanding these cell populations together with the mechanisms and pathways involved in the initiation and progression of tumorigenesis will be crucial for the advancement of the field of pituitary cancer biology. Furthermore, these advances could lead to the identification of diagnostic markers, translating into early detection of these tumors and more effective treatment in human patients. 


\section{Declaration of interest}

The authors declare that there is no conflict of interest that could be perceived as prejudicing the impartiality of this review.

\section{Acknowledgements}

GC is supported by a Child Health Research Appeal Trust studentship. JMGM is supported by CONACYT and UCL-CONACYT postgraduate fellowships. SH is supported by Wellcome Trust 4-year PhD studentship in Stem Cell and Developmental Biology.

\section{References}

Abdullah, L.N., Chow, E.K.-H., 2013. Mechanisms of chemoresistance in cancer stem cells.

Clin. Transl. Med. 2, 3. doi:10.1186/2001-1326-2-3

Aflorei, E.D., Korbonits, M., 2014. Epidemiology and etiopathogenesis of pituitary adenomas.

J. Neurooncol. 117, 379-394. doi:10.1007/s11060-013-1354-5

Al-Hajj, M., Wicha, M.S., Benito-Hernandez, A., Morrison, S.J., Clarke, M.F., 2003.

Prospective identification of tumorigenic breast cancer cells. Proc. Natl. Acad. Sci. U. S.

A. 100, 3983-8. doi:10.1073/pnas.0530291100

Alexander, J.M., Biller, B.M., Bikkal, H., Zervas, N.T., Arnold, A., Klibanski, A., 1990.

Clinically nonfunctioning pituitary tumors are monoclonal in origin. J. Clin. Invest. 86, 336-40. doi:10.1172/JCI114705

Alison, M.R., Murphy, G., Leedham, S., 2008. Stem cells and cancer: a deadly mix. Cell Tissue Res. 331, 109-24. doi:10.1007/s00441-007-0510-7

Andoniadou, C.L., Gaston-Massuet, C., Reddy, R., Schneider, R.P., Blasco, M. a, Le Tissier, P., Jacques, T.S., Pevny, L.H., Dattani, M.T., Martinez-Barbera, J.P., Pedro, J., 2012. Identification of novel pathways involved in the pathogenesis of human adamantinomatous craniopharyngioma. Acta Neuropathol. doi:10.1007/s00401-0120957-9

Andoniadou, C.L., Matsushima, D., Mousavy-gharavy, S.N., Signore, M., Mackintosh, A.I., Schaeffer, M., Gaston-massuet, C., Mollard, P., Jacques, T.S., Tissier, P. Le, Dattani, 
M.T., Pevny, L.H., Martinez-barbera, J.P., 2013. The Sox $2+$ population of the adult murine pituitary includes progenitor / stem cells with tumour-inducing potential. Cell Stem Cell.

Arwert, E.N., Lal, R., Quist, S., Rosewell, I., van Rooijen, N., Watt, F.M., 2010. Tumor formation initiated by nondividing epidermal cells via an inflammatory infiltrate. Proc.

Natl. Acad. Sci. U. S. A. 107, 19903-19908. doi:10.1073/pnas.1007404107

Arzt, E., Pereda, M.P., Castro, C.P., Pagotto, U., Renner, U., Stalla, G.K., 1999. Pathophysiological Role of the Cytokine Network in the Anterior Pituitary Gland. Front. Neuroendocrinol. 20, 71-95. doi:10.1006/frne.1998.0176

Barbieri, F., Bajetto, A., Porcile, C., Pattarozzi, A., Schettini, G., Florio, T., 2007. Role of stromal cell-derived factor 1 (SDF1/CXCL12) in regulating anterior pituitary function. J. Mol. Endocrinol. 38, 383-9. doi:10.1677/JME-06-0014

Barbieri, F., Thellung, S., Würth, R., Gatto, F., Corsaro, A., Villa, V., Nizzari, M., Albertelli, M., Ferone, D., Florio, T., W??rth, R., Gatto, F., Corsaro, A., Villa, V., Nizzari, M., Albertelli, M., Ferone, D., Florio, T., 2014. Emerging targets in pituitary adenomas: Role of the CXCL12/CXCR4-R7 system. Int. J. Endocrinol. 2014. doi:10.1155/2014/753524

Beck, B., Blanpain, C., 2013. Unravelling cancer stem cell potential. Nat. Rev. Cancer 13, 727738. doi:10.1038/nrc3597

Buch, H., El-Hadd, T., Bicknell, J., Simpson, D.J., Farrell, W.E., Clayton, R.N., 2002. Pituitary tumours are multiclonal from the outset: evidence from a case with dural metastases. Clin. Endocrinol. (Oxf). 56, 817-22.

Buslei, R., Hölsken, A., Hofmann, B., Kreutzer, J., Siebzehnrubl, F., Hans, V., Oppel, F., Buchfelder, M., Fahlbusch, R., Blümcke, I., 2007. Nuclear beta-catenin accumulation associates with epithelial morphogenesis in craniopharyngiomas. Acta Neuropathol. 113, 585-90. doi:10.1007/s00401-006-0184-3

Buslei, R., Nolde, M., Hofmann, B., Meissner, S., Eyupoglu, I.Y., Siebzehnrübl, F., Hahnen, E., Kreutzer, J., Fahlbusch, R., 2005. Common mutations of beta-catenin in adamantinomatous craniopharyngiomas but not in other tumours originating from the sellar region. Acta Neuropathol. 109, 589-97. doi:10.1007/s00401-005-1004-x

Castinetti, F., Davis, S.W., Brue, T., Camper, S. a, 2011. Pituitary stem cell update and potential implications for treating hypopituitarism. Endocr. Rev. 32, 453-71. doi:10.1210/er.2010-0011

Chatzellis, E., Alexandraki, K.I., Androulakis, I.I., Kaltsas, G., 2015. Aggressive pituitary tumors. Neuroendocrinology 101, 87-104. doi:10.1159/000371806 
Chen, J., Gremeaux, L., Fu, Q., Liekens, D., Van Laere, S., Vankelecom, H., 2009. Pituitary progenitor cells tracked down by side population dissection. Stem Cells 27, 1182-1195. doi:10.1002/stem.51

Chen, J., Hersmus, N., Duppen, V. Van, Caesens, P., Denef, C., Vankelecom, H., 2005. The Adult Pituitary Contains a Cell Population Displaying Stem/Progenitor Cell and Early Embryonic Characteristics. Endocrinology 146, 3985-3998. doi:10.1210/en.2005-0185

Chen, L., Ye, H., Wang, X., Tang, X., Mao, Y., Zhao, Y., Wu, Z., Mao, X.O., Xie, L., Jin, K., Yao, Y., 2014. Evidence of brain tumor stem progenitor-like cells with low proliferative capacity in human benign pituitary adenoma. Cancer Lett. 349, 61-66. doi:10.1016/j.canlet.2014.03.031

Clarke, M.F., Fuller, M., 2006. Stem cells and cancer: two faces of eve. Cell 124, 1111-5. doi:10.1016/j.cell.2006.03.011

Clayton, R.N., Farrell, W.E., 2006. Clonality of Pituitary Tumours: More Complicated than Initially Envisaged? Brain Pathol. 11, 313-327. doi:10.1111/j.1750-3639.2001.tb00402.x

Clayton, R.N., Pfeifer, M., Atkinson, A.B., Belchetz, P., Wass, J.A., Kyrodimou, E., Vanderpump, M., Simpson, D., Bicknell, J., Farrell, W.E., 2000. Different patterns of allelic loss (loss of heterozygosity) in recurrent human pituitary tumors provide evidence for multiclonal origins. Clin. Cancer Res. 6, 3973-82.

Clevers, H., 2011. The cancer stem cell: premises, promises and challenges. Nat. Med. 17, 313-9. doi:10.1038/nm.2304

Dasen, J.S., Rosenfeld, M.G., 2001. Signaling and transcriptional mechanisms in pituitary development. Annu. Rev. Neurosci. 24, 327-55.

Del Basso De Caro, M., Solari, D., Pagliuca, F., Villa, A., Guadagno, E., Cavallo, L.M., Colao, A., Pettinato, G., Cappabianca, P., 2016. Atypical pituitary adenomas: clinical characteristics and role of ki-67 and p53 in prognostic and therapeutic evaluation. A series of 50 patients. Neurosurg. Rev. doi:10.1007/s10143-016-0740-9

Denef, C., 2008. Paracrinicity: the story of 30 years of cellular pituitary crosstalk. J. Neuroendocrinol. 20, 1-70. doi:10.1111/j.1365-2826.2007.01616.x

Deschene, E.R., Myung, P.S., Rompolas, P., Zito, G., Sun, T.Y.T., Taketo, M.M., Saotome, I., Greco, V., 2014. Beta-Catenin Activation Regulates Tissue Growth Non-Cell Autonomously in the Hair Stem Cell Niche. Science (80-. ). 343, 1353-1356. doi:10.1126/science. 1248373

Di Leva, A., Rotondo, F., Syro, L. V., Cusimano, M.D., Kovacs, K., 2014. Aggressive pituitary adenomas-diagnosis and emerging treatments. Nat. Rev. Endocrinol. 10, 423-435. 
doi:10.1038/nrendo.2014.64

Donangelo, I., Ren, S.G., Eigler, T., Svendsen, C., Melmed, S., 2014. Sca1+ murine pituitary adenoma cells show tumor-growth advantage. Endocr. Relat. Cancer 21, 203-216. doi:10.1530/ERC-13-0229

Drouin, J., 2011. Pituitary Development, in: The Pituitary. Elsevier, London, pp. 3-14.

Fauquier, T., Rizzoti, K., Dattani, M., Lovell-Badge, R., Robinson, I.C.A.F., 2008. SOX2expressing progenitor cells generate all of the major cell types in the adult mouse pituitary gland. Proc. Natl. Acad. Sci. U. S. A. 105, 2907-12. doi:10.1073/pnas.0707886105

Fujita, T., Chiwaki, F., Takahashi, R., Aoyagi, K., Yanagihara, K., Nishimura, T., Tamaoki, M., Komatsu, M., Komatsuzaki, R., Matsusaki, K., Ichikawa, H., Sakamoto, H., Yamada, Y., Fukagawa, T., Katai, H., Konno, H., Ochiya, T., Yoshida, T., Sasaki, H., 2015. Identification and Characterization of CXCR4-Positive Gastric Cancer Stem Cells. PLoS One 10, e0130808. doi:10.1371/journal.pone.0130808

Gadelha, M.R., Diem, M., Hernández-Ramírez, L.C., Korbonits, M., 2013. Genetics of pituitary adenomas. Endocr. Tumor Syndr. Their Genet. 41, 111-140. doi:10.1159/000345673

Galichet, C., Lovell-Badge, R., Rizzoti, K., 2010. Nestin-Cre mice are affected by hypopituitarism, which is not due to significant activity of the transgene in the pituitary gland. PLoS One 5, e11443. doi:10.1371/journal.pone.0011443

Garcia-Lavandeira, M., Diaz-Rodriguez, E., Bahar, D., Garcia-Rendueles, A.R., Rodrigues, J.S., Dieguez, C., Alvarez, C. V., 2015. Pituitary Cell Turnover: From Adult Stem Cell Recruitment through Differentiation to Death. Neuroendocrinology 101, 175-192. doi:10.1159/000375502

Garcia-Lavandeira, M., Quereda, V., Flores, I., Saez, C., Diaz-Rodriguez, E., Japon, M.A., Ryan, A.K., Blasco, M.A., Dieguez, C., Malumbres, M., Alvarez, C. V, 2009. A GRFa2/Prop1/stem (GPS) cell niche in the pituitary. PLoS One 4, e4815. doi:10.1371/journal.pone.0004815

Garcia-Lavandeira, M., Saez, C., Diaz-Rodriguez, E., Perez-Romero, S., Senra, A., Dieguez, C., Japon, M.A., Alvarez, C. V., 2011. Craniopharyngiomas Express Embryonic Stem Cell Markers (SOX2, OCT4, KLF4, and SOX9) as Pituitary Stem Cells but Do Not Coexpress RET/GFRA3 Receptors. J. Clin. Endocrinol. Metab. 97, 1-8. doi:10.1210/jc.2011-2187

Gaston-Massuet, C., Andoniadou, C.L., Massimo, S., Jayakody, S.A., Charolidi, N., Kyeyune, R., Vernay, B., Jacques, T.S., Taketo, M.M., Le Tissier, P., Dattani, M.T., Martinez- 
Barbera, J.P., 2011. Increased Wingless (Wnt) signaling in pituitary progenitor/stem cells gives rise to pituitary tumors in mice and humans. Proc. Natl. Acad. Sci. U. S. A. 1088, 11482-7. doi:10.1073/pnas.1101553108

Gleiberman, A.S., Michurina, T., Encinas, J.M., Roig, J.L., Krasnov, P., Balordi, F., Fishell, G., Rosenfeld, M.G., Enikolopov, G., 2008. Genetic approaches identify adult pituitary stem cells. Proc. Natl. Acad. Sci. U. S. A. 105, 6332-7. doi:10.1073/pnas.0801644105

Goodell, M.A., Brose, K., Paradis, G., Conner, A.S., Mulligan, R.C., 1996. Isolation and Functional Properties of Murine Hematopoietic Stem Cells that are Replicating in Vivo. J. Exp. Med. 183, 1797-806.

Graciarena, M., Carbia-Nagashima, A., Onofri, C., Perez-Castro, C., Giacomini, D., Renner, U., Stalla, G.K., Arzt, E., 2004. Involvement of the gp130 cytokine transducer in MtT/S pituitary somatotroph tumour development in an autocrine-paracrine model. Eur. J. Endocrinol. 151, 595-604.

Gremeaux, L., Fu, Q., Chen, J., Vankelecom, H., 2012. Activated phenotype of the pituitary stem/progenitor cell compartment during the early-postnatal maturation phase of the gland. Stem Cells Dev. 21, 801-13. doi:10.1089/scd.2011.0496

Guo, W., Lasky, J.L., Chang, C.-J., Mosessian, S., Lewis, X., Xiao, Y., Yeh, J.E., Chen, J.Y., Iruela-Arispe, M.L., Varella-Garcia, M., Wu, H., 2008. Multi-genetic events collaboratively contribute to Pten-null leukaemia stem-cell formation. Nature 453, 52933. doi:10.1038/nature06933

Herman, V., Fagin, J., Gonsky, R., Kovacs, K., Melmed, S., 1990. Clonal origin of pituitary adenomas. J. Clin. Endocrinol. Metab. 71, 1427-33. doi:10.1210/jcem-71-6-1427

Hermann, P.C., Huber, S.L., Herrler, T., Aicher, A., Ellwart, J.W., Guba, M., Bruns, C.J., Heeschen, C., 2007. Distinct Populations of Cancer Stem Cells Determine Tumor Growth and Metastatic Activity in Human Pancreatic Cancer. Cell Stem Cell 1, 313-323. doi:10.1016/j.stem.2007.06.002

Higuchi, M., Yoshida, S., Ueharu, H., Chen, M., Kato, T., Kato, Y., 2014. PRRX1 and PRRX2 distinctively participate in pituitary organogenesis and a cell-supply system. Cell Tissue Res. 357, 323-335. doi:10.1007/s00441-014-1861-5

Hofmann, B.M., Kreutzer, J., Saeger, W., Buchfelder, M., Blümcke, I., Fahlbusch, R., Buslei, R., 2006. Nuclear beta-catenin accumulation as reliable marker for the differentiation between cystic craniopharyngiomas and rathke cleft cysts: a clinico-pathologic approach. Am. J. Surg. Pathol. 30, 1595-603. doi:10.1097/01.pas.0000213328.64121.12

Hölsken, A., Stache, C., Schlaffer, S.M., Flitsch, J., Fahlbusch, R., Buchfelder, M., Buslei, R., 
2013. Adamantinomatous craniopharyngiomas express tumor stem cell markers in cells with activated Wnt signaling: further evidence for the existence of a tumor stem cell niche? Pituitary 17, 546-56. doi:10.1007/s11102-013-0543-8

Horiguchi, K., Ilmiawati, C., Fujiwara, K., Tsukada, T., Kikuchi, M., Yashiro, T., 2012. Expression of Chemokine CXCL12 and Its Receptor CXCR4 in Folliculostellate (FS) Cells of the Rat Anterior Pituitary Gland: The CXCL12/CXCR4 Axis Induces Interconnection of FS Cells. Endocrinology 153, 1717-1724. doi:10.1210/en.2011-1937

Hsu, Y.-C., Li, L., Fuchs, E., 2014. Emerging interactions between skin stem cells and their niches. Nat. Med. 20, 847-856. doi:10.1038/nm.3643

Jung, M.-J., Rho, J.-K., Kim, Y.-M., Jung, J.E., Jin, Y.B., Ko, Y.-G., Lee, J.-S., Lee, S.-J., Lee, J.C., Park, M.-J., 2013. Upregulation of CXCR4 is functionally crucial for maintenance of stemness in drug-resistant non-small cell lung cancer cells. Oncogene 32, 209-221. doi:10.1038/onc.2012.37

Karavitaki, N., 2012. Prevalence and incidence of pituitary adenomas. Ann. Endocrinol. (Paris). 73, 79-80. doi:10.1016/j.ando.2012.03.039

Kode, A., Manavalan, J.S., Mosialou, I., Bhagat, G., Rathinam, C. V, Luo, N., Khiabanian, H., Lee, A., Murty, V. V, Friedman, R., Brum, A., Park, D., Galili, N., Mukherjee, S., TeruyaFeldstein, J., Raza, A., Rabadan, R., Berman, E., Kousteni, S., 2014. Leukaemogenesis induced by an activating $\beta$-catenin mutation in osteoblasts. Nature 506, 240-4. doi:10.1038/nature12883

Kreso, A., Dick, J.E.J., 2014. Evolution of the cancer stem cell model. Cell Stem Cell 14, 275291. doi:10.1016/j.stem.2014.02.006

Krylyshkina, O., Chen, J., Mebis, L., Denef, C., Vankelecom, H., 2005. Nestinimmunoreactive cells in rat pituitary are neither hormonal nor typical folliculo-stellate cells. Endocrinology 146, 2376-2387. doi:10.1210/en.2004-1209

Lepore, D.A., Roeszler, K., Wagner, J., Ross, S.A., Bauer, K., Thomas, P.Q., 2005. Identification and enrichment of colony-forming cells from the adult murine pituitary. Exp. Cell Res. 308, 166-176. doi:10.1016/j.yexcr.2005.04.023

Lines, K.E., Stevenson, M., Thakker, R. V., 2016. Animal models of pituitary neoplasia. Mol. Cell. Endocrinol. 421, 68-81. doi:10.1016/j.mce.2015.08.024

Lujambio, A., Akkari, L., Simon, J., Grace, D., Tschaharganeh, D.F., Bolden, J.E., Zhao, Z., Thapar, V., Joyce, J. a, Krizhanovsky, V., Lowe, S.W., 2013. Non-cell-autonomous tumor suppression by p53. Cell 153, 449-60. doi:10.1016/j.cell.2013.03.020

Ma, W., Ikeda, H., Yoshimoto, T., 2002. Clinicopathologic study of 123 cases of prolactin- 
secreting pituitary adenomas with special reference to multihormone production and clonality of the adenomas. Cancer 95, 258-66. doi:10.1002/cncr.10676

Melmed, S., 2015. Pituitary Tumors. Endocrinol. Metab. Clin. NA 44, 208-236. doi:10.1016/j.ecl.2014.11.004

Mertens, F., Gremeaux, L., Chen, J., Fu, Q., Willems, C., Roose, H., Govaere, O., Roskams, T., Cristina, C., Becú-Villalobos, D., Jorissen, M., Poorten, V. Vander, Bex, M., van Loon, J., Vankelecom, H., 2015. Pituitary tumors contain a side population with tumor stem cell-associated characteristics. Endocr. Relat. Cancer 22, 481-504. doi:10.1530/ERC-14-0546

Müller, H.L., 2014. Childhood craniopharyngioma: treatment strategies and outcomes. Expert Rev. Neurother. 14, 187-97. doi:10.1586/14737175.2014.875470

Müller, H.L., 2010. Childhood craniopharyngioma--current concepts in diagnosis, therapy and follow-up. Nat. Rev. Endocrinol. 6, 609-18. doi:10.1038/nrendo.2010.168

Nakanishi, Y., Seno, H., Fukuoka, A., Ueo, T., Yamaga, Y., Maruno, T., Nakanishi, N., Kanda, K., Komekado, H., Kawada, M., Isomura, A., Kawada, K., Sakai, Y., Yanagita, M., Kageyama, R., Kawaguchi, Y., Taketo, M.M., Yonehara, S., Chiba, T., 2013. Dclk1 distinguishes between tumor and normal stem cells in the intestine. Nat. Genet. 45, 98103. doi:10.1038/ng.2481

Nguyen, L. V, Vanner, R., Dirks, P., Eaves, C.J., 2012. Cancer stem cells: an evolving concept. Nat. Rev. Cancer 12, 133-43. doi:10.1038/nrc3184

Nicolas, M., Wolfer, A., Raj, K., Kummer, J.A., Mill, P., van Noort, M., Hui, C., Clevers, H., Dotto, G.P., Radtke, F., 2003. Notch1 functions as a tumor suppressor in mouse skin. Nat. Genet. 33. doi:10.1038/ng1099

Nomura, R., Yoshida, D., Teramoto, A., 2009. Stromal cell-derived factor-1 expression in pituitary adenoma tissues and upregulation in hypoxia. J. Neurooncol. 94, 173-81. doi:10.1007/s11060-009-9835-2

Orciani, M., Davis, S., Appolloni, G., Lazzarini, R., Mattioli-Belmonte, M., Ricciuti, R. a, Boscaro, M., Di Primio, R., Arnaldi, G., 2015. Isolation and characterization of progenitor mesenchymal cells in human pituitary tumors. Cancer Gene Ther. 22, 9-16. doi:10.1038/cgt.2014.63

Patel, D.M., Shah, J., Srivastava, A.S., 2013. Therapeutic potential of mesenchymal stem cells in regenerative medicine. Stem Cells Int. 2013, 496218. doi:10.1155/2013/496218

Pérez Millán, M.I., Brinkmeier, M.L., Mortensen, A.H., Camper, S.A., 2016. PROP1 triggers epithelial-mesenchymal transition-like process in pituitary stem cells. Elife 5, e14470. 
doi:10.7554/eLife. 14470

Puck, T.T., Marcus, P.I., 1956. Action of x-rays on mammalian cells. J. Exp. Med. 103, 65366.

Rizzoti, K., Akiyama, H., Lovell-Badge, R., 2013. Mobilized Adult Pituitary Stem Cells Contribute to Endocrine Regeneration in Response to Physiological Demand. Cell Stem Cell 13, 419-432. doi:10.1016/j.stem.2013.07.006

Rogelj, S., Weinberg, R.A., Fanning, P., Klagsbrun, M., 1988. Basic fibroblast growth factor fused to a signal peptide transforms cells. Nature 331. doi:10.1038/331173a0

Sato, Y., Hashitani, H., Shirasawa, N., Sakuma, E., Naito, A., Suzuki, H., Asai, Y., Sato, G., Wada, I., Herbert, D.C., Soji, T., 2005. Intercellular communications within the rat anterior pituitary XII: immunohistochemical and physiological evidences for the gap junctional coupling of the folliculo-stellate cells in the rat anterior pituitary. Tissue Cell 37, 281-91. doi:10.1016/j.tice.2005.03.005

Schepers, A.G., Snippert, H.J., Stange, D.E., van den Born, M., Es, J.H. van, Wetering, M. van de, Clevers, H., 2012. Lineage Tracing Reveals Lgr5+ Stem Cell Activity in Mouse Intestinal Adenomas. Science (80-. ). 337, 449-452.

Schulte, H.M., Oldfield, E.H., Allolio, B., Katz, D.A., Berkman, R.A., Ali, I.U., 1991. Clonal composition of pituitary adenomas in patients with Cushing's disease: determination by X-chromosome inactivation analysis. J. Clin. Endocrinol. Metab. 73, 1302-8. doi:10.1210/jcem-73-6-1302

Shlomo Melmed, 2011. Pathogenesis of pituitary tumors. Nat. Rev. Endocrinol. 7, 207-227. doi:10.1146/annurev.pathol.4.110807.092259

Soji, T., Mabuchi, Y., Kurono, C., Herbert, D.C., 1997. Folliculo-stellate cells and intercellular communication within the rat anterior pituitary gland. Microsc. Res. Tech. 39, 138-49. doi:10.1002/(SICI)1097-0029(19971015)39:2<138::AID-JEMT5>3.0.CO;2-H

Stange, D.E., Clevers, H., 2013. Concise review: the yin and yang of intestinal (cancer) stem cells and their progenitors. Stem Cells 31, 2287-95. doi:10.1002/stem.1475

Susa, T., Kato, T., Yoshida, S., Yako, H., Higuchi, M., Kato, Y., 2012. Paired-related homeodomain proteins Prx1 and Prx2 are expressed in embryonic pituitary stem/progenitor cells and may be involved in the early stage of pituitary differentiation. J. Neuroendocrinol. 24, 1201-12. doi:10.1111/j.1365-2826.2012.02336.x

Trautmann, F., Cojoc, M., Kurth, I., Melin, N., Bouchez, L.C., Dubrovska, A., Peitzsch, C., 2014. CXCR4 as biomarker for radioresistant cancer stem cells. Int. J. Radiat. Biol. 90, 687-99. doi:10.3109/09553002.2014.906766 
Uhrbom, L., Hesselager, G., Nistér, M., Westermark, B., 1998. Induction of brain tumors in mice using a recombinant platelet-derived growth factor B-chain retrovirus. Cancer Res. 58, 5275-9.

Valent, P., Bonnet, D., De Maria, R., Lapidot, T., Copland, M., Melo, J. V, Chomienne, C., Ishikawa, F., Schuringa, J.J., Stassi, G., Huntly, B., Herrmann, H., Soulier, J., Roesch, A., Schuurhuis, G.J., Wöhrer, S., Arock, M., Zuber, J., Cerny-Reiterer, S., Johnsen, H.E., Andreeff, M., Eaves, C., 2012. Cancer stem cell definitions and terminology: the devil is in the details. Nat. Rev. Cancer 12,767-75. doi:10.1038/nrc3368

van Es, J.H., Sato, T., van de Wetering, M., Lyubimova, A., Nee, A.N.Y., Gregorieff, A., Sasaki, N., Zeinstra, L., van den Born, M., Korving, J., Martens, A.C.M., Barker, N., van Oudenaarden, A., Clevers, H., 2012. D111+ secretory progenitor cells revert to stem cells upon crypt damage. Nat. Cell Biol. 14, 1099-104. doi:10.1038/ncb2581

Vankelecom, H., 2010. Pituitary stem/progenitor cells: embryonic players in the adult gland? Eur. J. Neurosci. 32, 2063-81. doi:10.1111/j.1460-9568.2010.07523.x

Vankelecom, H., 2007. Non-hormonal cell types in the pituitary candidating for stem cell. Semin. Cell Dev. Biol. 18, 559-570. doi:10.1016/j.semcdb.2007.04.006

Vankelecom, H., Chen, J., 2013. Pituitary stem cells: Where do we stand? Mol. Cell. Endocrinol. doi:10.1016/j.mce.2013.08.018

Visvader, J.E., Lindeman, G.J., 2008. Cancer stem cells in solid tumours: accumulating evidence and unresolved questions. Nat. Rev. Cancer 8, 755-768. doi:10.1038/nrc2499

Weiss, S., Siebzehnrubl, F.A., Kreutzer, J., Blumcke, I., Buslei, R., 2009. Evidence for a progenitor cell population in the human pituitary. Clin Neuropathol 28, 309-318.

Würth, R., Bajetto, A., Harrison, J.K., Barbieri, F., Florio, T., 2014. CXCL12 modulation of CXCR4 and CXCR7 activity in human glioblastoma stem-like cells and regulation of the tumor microenvironment. Front. Cell. Neurosci. 8, 144. doi:10.3389/fncel.2014.00144

Würth, R., Barbieri, F., Pattarozzi, A., Gaudenzi, G., Gatto, F., Fiaschi, P., Ravetti, J.-L., Zona, G., Daga, A., Persani, L., Ferone, D., Vitale, G., Florio, T., 2016. Phenotypical and Pharmacological Characterization of Stem-Like Cells in Human Pituitary Adenomas. Mol. Neurobiol. doi:10.1007/s12035-016-0025-x

Xu, Q., Yuan, X., Tunici, P., Liu, G., Fan, X., Xu, M., Hu, J., Hwang, J.Y., Farkas, D.L., Black, K.L., Yu, J.S., 2009. Isolation of tumour stem-like cells from benign tumours. Br. J. Cancer 101, 303-11. doi:10.1038/sj.bjc.6605142

Yoshida, S., Kato, T., Kato, Y., 2016. Regulatory system for stem/progenitor cell niches in the adult rodent pituitary. Int. J. Mol. Sci. 17. doi:10.3390/ijms17010075 
Yoshida, S., Kato, T., Susa, T., Cai, L., Nakayama, M., Kato, Y., 2009. PROP1 coexists with SOX2 and induces PIT1-commitment cells, Biochemical and Biophysical Research Communications. doi:10.1016/j.bbrc.2009.05.027

Zhou, C., Jiao, Y., Wang, R., Ren, S.-G., Wawrowsky, K., Melmed, S., 2015. STAT3 upregulation in pituitary somatotroph adenomas induces growth hormone hypersecretion. J. Clin. Invest. 125, 1-11. doi:10.1172/JCI78173.)

Zhu, X., Gleiberman, A.S., Rosenfeld, M.G., 2007. Molecular Physiology of Pituitary Development: Signaling and Transcriptional Networks. Physiol. Rev. 87, 933-963. doi:10.1152/physrev.00006.2006.

Zomer, A., Ellenbroek, S.I.J., Ritsma, L., Beerling, E., Vrisekoop, N., Van Rheenen, J., 2013. Brief report: Intravital imaging of cancer stem cell plasticity in mammary tumors. Stem Cells 31, 602-606. doi:10.1002/stem.1296 